\title{
Umberto Eco, Migración e intolerancia, Madrid: Lumen, 2019, pp.78.
}

Este libro es un recopilatorio de cuatro ponencias dictadas por Umberto Eco, abordando los fenómenos migratorios y la intolerancia en la Europa de los siglos XX y XXI, como temas centrales y transversales a los principales debates políticos contemporáneos.

La primera de las ponencias, "Las migraciones del tercer milenio", dictada en 1997, gira en torno a la distinción entre el concepto de "inmigración" y "migración", entendiendo que el primer concepto hace referencia a un fenómeno que se puede controlar políticamente y en el que la población se introduce dentro de la nueva sociedad a la que llega. El concepto de "migración" lo aplica el autor para situaciones en las que el flujo de población cambia la cultura del territorio al que migra. Umberto Eco entiende que Europa está atravesada por este segundo fenómeno que creará paulatinamente un continente multicultural, "coloreado" (p. 30), poniendo el foco de atención sobre la "intolerancia" como uno de los grandes retos aún pendientes, de ahí la importancia de la segunda ponencia.

La segunda ponencia titulada "Intolerancia", aborda en primera instancia el fundamentalismo, analizando las características del mismo y su relación con el integrismo, conceptos a menudo confundidos, pero en sus prácticas no necesariamente tienen que ir de la mano. Se llega así al concepto de intolerancia, concebida sobre "raíces biológicas" y basada en "reacciones emotivas a menudo superficiales" (p. 41). Un concepto que refiere a una práctica difícil de "ponerle freno con argumentos racionales" (p. 44), siendo por ello imprescindible la educación desde la primera infancia en valores que prevengan todo atisbo de intolerancia.

La tercera ponencia, bajo el nombre de "Un nuevo Tratado de Nimega", aborda la constante lucha contra la intolerancia en Europa y la manera en la que se construyó un espacio de convivencia dentro del continente, a pesar de un pasado de guerras internas entre las distintas regiones que conforman un todo en la actualidad, guardando las particularidades de los distintos países. Un nuevo Tratado de Nimega conformaría un nuevo pacto por la convivencia, que proporcionaría garantías ciudadanas ante posibles arrebatos de intolerancia y racismo.

Por último, la ponencia titulada "Experiencias de antropología recíproca", aborda el papel de la antropología desde una práctica de reciprocidad entre las partes implicadas, como herramienta de intercambio de percepciones sobre los contextos que consideramos propios y habitables. El autor plantea que ante el racismo como "forma patológica de reacción natural ante la diversidad" (p. 72), se hace apremiante una herramienta como la que ofrece la "antropología recíproca" como forma de aceptar la diferencia, entendiéndola como constitutiva de la diversidad, con la finalidad de comprender al "otro" y eliminar así el racismo.

La relevancia de esta obra se enmarca en la actualidad de los planteamientos que en ella se recogen. Se trata de ponencias realizadas hace más de una década en algunos casos, no obstante, el paso del tiempo parece solo haber contribuido a hacer paulatinamente más apremiante la búsqueda de respuestas ante los crecientes atisbos de intolerancia que se extienden a lo largo de Europa. A ello contribuyen los dos últimos escritos, a ofrecer vías efectivas para enfrentar el racismo y la intolerancia.

Entre lo teórico y lo prepositivo, siempre desde la ligera lectura que ofrece un escrito basado en una presentación pública, Umberto Eco facilita un diagnóstico orientado a llegar al fondo de las manifestaciones de odio, discriminación e intolerancia que se han puesto en práctica con mayor virulencia en los últimos años en Europa. La educación desde la infancia es identificada como la pieza fundamental que posibilitaría construir unos cimientos más sólidos sobre los que desarrollar una solidaridad diversa, que se reconozca en la diferencia. Así y solo así, se podría caminar hacia el fin de la intolerancia.

Ivana Belén Ruiz Estramil.

Universidad Pública de Navarra.

ivanabelenrues@gmail.com 